\title{
Disruptive Technology: The Future of SMS Technology
}

\author{
Cik Ku Haroswati Che Ku Yahaya ${ }^{1}$, Murizah Kassim² ${ }^{2}$ Hasnorhafiza Husni ${ }^{3}$ \\ ${ }^{1,3}$ Centre of Foundation Study, Campus Dengkil, Universiti Teknologi MARA (UiTM), Shah Alam, \\ Selangor, Malaysia \\ ${ }^{2}$ Faculty of Electrical Engineering, Universiti Teknologi MARA (UiTM), Shah Alam, Selangor, Malaysia
}

\begin{tabular}{|c|c|}
\hline Article Info & ABSTRACT \\
\hline Article history: & \multirow{10}{*}{$\begin{array}{l}\text { The research illustrates a view on the current trends in the telecommunication } \\
\text { industry focusing on the matter of Short Message Service (SMS) technology. } \\
\text { It targets and explains disruptive technology and also introduces disruptive } \\
\text { technology in Short Message Service (SMS). The methodology of this } \\
\text { research is market trend analysis using data on volume of Short Message } \\
\text { Service (SMS) sent and received through a mobile network and a survey that } \\
\text { was conducted with questionnaires. The findings are Short Message Service } \\
\text { (SMS) is predicted to become obsolete and be disrupted by Over the Top } \\
\text { (OTT) messaging application by the third quarter of the year 2020. This was } \\
\text { implemented with linear regression prediction. By the survey a new trend of } \\
\text { using Short Message Service (SMS) has emerged but users have certainly } \\
\text { moved away from SMS and now prefer texting Over the Top (OTT) } \\
\text { messaging applications. }\end{array}$} \\
\hline Received Feb 1, 2018 & \\
\hline Revised Apr 20, 2018 & \\
\hline Accepted Apr 27, 2018 & \\
\hline Keywords: & \\
\hline Disruptive technology & \\
\hline Linear regression prediction & \\
\hline Mobile internet data & \\
\hline OTT messaging applications & \\
\hline SMS & \\
\hline
\end{tabular}

Copyright (c) 2018 Institute of Advanced Engineering and Science. All rights reserved.

\section{Corresponding Author:}

Cik Ku Haroswati Che Ku Yahaya, Centre of Foundation Study, Campus Dengkil, Universiti Teknologi MARA (UiTM), Shah Alam, Selangor, Malaysia.

Email: haroswati@salam.uitm.edu.my

\section{INTRODUCTION}

Disruptive Technology was first introduced by Clayton M Christensen in his article titled Disruptive Technologies: Catching the wave. The articles described the disruptive technology as any kind of new technology regardless of its industry, that will replaced the existing established market [1]. Nowadays, people are no longer talking about mini-computer or mainframe due to the disrupted technology called personal computer. Technologies that are available today are far superior to what it were in the 80's.

With the initial boom of smartphones worldwide in 2007 until today it has resulted in variety of smartphones with different specifications to choose from, and with this a certain technology is endangered to die out. Whichever combination of specification on a smartphone chosen by a consumer, there is one thing that almost all smartphones can support that is a text messaging application. All of this third-party messaging tools are supported by over-the-top (OTT) technology (via the internet) has threatened the Short Message Service (SMS) industry as a whole [2].

The first Short Message Service (SMS) to be sent was a text message from a computer of a test engineer to Richard Jarvis through the Vodafone Cellular network on the 2nd December 1992 [3]. The Short Message Service (SMS) simply read 'Merry Christmas'. The technology took a long time before it was widely used, but with almost all mobile phones equipped with Global System for Mobile (GSM) capabilities it was only time until it would be a profitable industry. The industry is now on rocky waters as consumers are now all shifting to over-the-top (OTT) messaging applications.

Though Christensen went on to release a second book called The Innovator's Solution where he replaced the term Disruptive Technology with Disruptive Innovation, many have faulted him not giving a precise and consistent definition on disruptive innovation. Many have disputed him but many have also supported his views with their own contributions to the theory. The first noteworthy contributions are by 
Vijay Govindarajan and Praveen K. Kopalle. It is noted that Christensen stated that disruptive technologies are cheaper and simpler and Ron Adner also stated in 'When Are Technologies Disruptive?' that a disruptive technology with its low performance cater to a niche for low-end and low-profit part of the market [4], [5].

Govindarajan and Kopalle went ahead and added to the theory that this is not always the case. The simplest example is the emergence of mobile phones. Mobile phones are considered a disruptive technology, but even so mobile phones were neither superior nor the cheaper alternative [4]. Mobile phones entered the market with unsatisfactory cellular service and high price but managed to disrupt the market after cellular coverage was improved and customers found it satisfactory to the high price it yielded [4].

A Reflective Review of Disruptive Innovation Theory by Yu Dan and Hang Chang Chieh stated that a disruptive innovation is relative, what is disruptive to one business can be a sustaining one for another. It also highlights that disruptors do not always replace traditional businesses, as an example photographers do not tolerate the inferior quality of digital photos but digital cameras are widely common amongst nonprofessionals. This results in the niche market that the film industry is in traditional media for photography is widely used. This paper also explains the distinction disruptive innovation versus destructive innovation. Destructive innovation is classified as an innovation that are both improving the technology by a tenfold and is kept low-cost. This kind innovation is destructive but not disruptive because it forces other competitors no other option but to follow suit [6].

\subsection{Background Study}

The concept of Short Message Service (SMS) was first introduced by Friedhelm Hillebrand in the 80's when the framework for Global System for Mobile (GSM) was optimized for telephony. The reason behind this because there was a huge interest in a non-voice service and the initial objective of keeping Global System for Mobile (GSM) technology low-cost to appeal to mass consumers [7]. Short Message Service (SMS) has been one of the most successful telecommunication technologies to date.

Although certain people starting to believe SMS technology to be dying out, Brenda Suarez thinks otherwise. In an article she wrote, she outlined three major reasons why message over IP is not going anywhere. The first is what made SMS so attractive it is the communication protocols that are in place for GSM, every mobile phone has the ability to send a text [8]. Any device with Global System for Mobile (GSM) capabilities can send a text. Second is the questionable high-cost for cellular data that is needed to support message over IP [8]. Next is the reliability of message over IP versus SMS because if there is no obvious reason for a mass shift from SMS, consumers will stick to what they traditionally are familiar with [8].

In a report published by an analyst Chetan Sharma, there is a slight dip in Short Message Service (SMS) usage in the US in 2012 [9] [10]. This is also evident in the trend of business that are taking the advantage of message over IP and cutting Short Message Service (SMS) usage for cost purposes [10].

Even with many sceptics about Short Message Service (SMS) will ever be disrupted a report called the future of mobile messaging: Over-the-top competitors threaten Short Message Service (SMS) by Mckinsey \& Company paints a different story. Netherlands and South Korea were the first two countries to experience a large dip in Short Message Service (SMS) volumes when OTT messaging applications were introduced. In 2011 when WhatsApp's penetration level jumped from a mere 5 percent to 85 percent, carriers in Netherlands saw an 11 percent decline in Short Message Service (SMS) volume per subscriber compared to the 33 percent increase from the last two quarters [11]. Around the same year carriers in South Korea also experience more severe case of dipping when Kakaotalk was introduced. It caused a 55 percent dip in the volume of Short Message Service (SMS) [11].

\section{METHODOLOGY}

\subsection{Market Trend Analysis}

In researching the disrupted Short Message Service (SMS) trends, the telecommunication market has to be analysed. For this particular topic, the first set of data that will be analysed is the volume of Short Message Service (SMS) sent and received over a mobile network.

Figure 1 show the process to complete a linear regression test with Pearson's correlation efficient. By determining the linear regression equation of $\mathrm{y}=\mathrm{mx}+\mathrm{b}$, a prediction can be made when Short Message Service (SMS) will become obsolete and data is sourced from Infocomm Media Development Authority and used under the Singapore Open Data License.

Equation (1) illustrates the formula for the correlation coefficient. Correlation coefficient formulas are used to find how strong a relationship is between data. The formulas return a value between -1 and 1 , where 1 indicates a strong positive relationship, -1 indicates a strong negative relationship and a result of zero indicates no relationship at all. 


$$
r=\frac{n\left(\sum x y\right)-\left(\sum x\right)\left(\sum y\right)}{\left.\sqrt{[n} \sum x^{2}-\left(\sum x\right)^{2}\right]\left[n \sum y^{2}-\left(\sum y\right)^{2}\right]}
$$

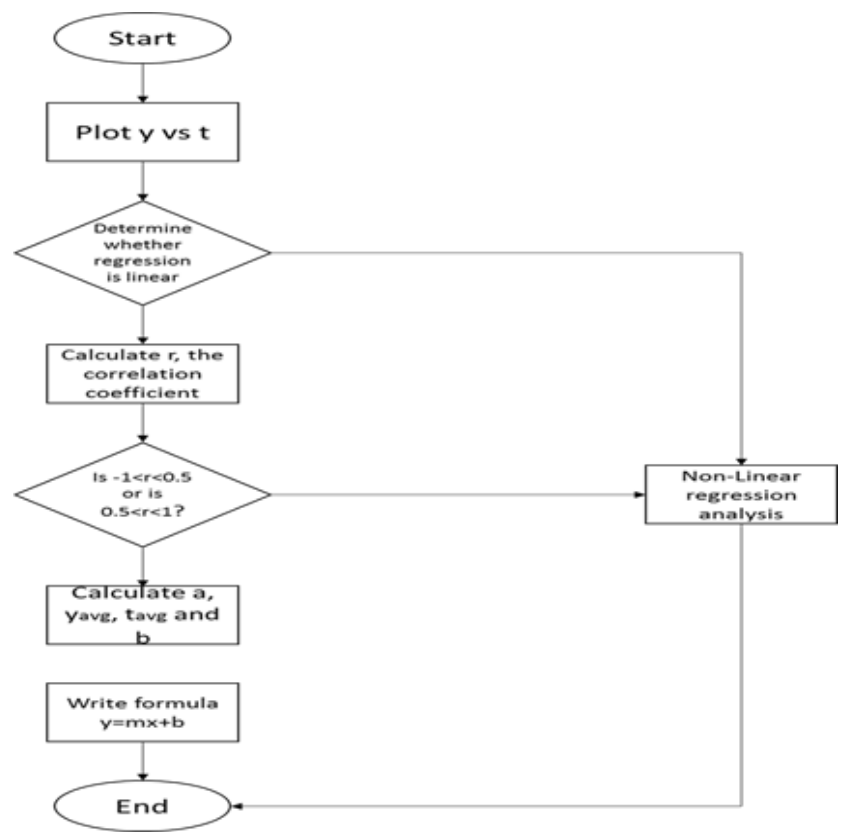

Figure 1. Flowchart of Market Trend Analysis with Linear Regression and Pearson's Correlation Coefficient

\subsection{Survey}

The data for this research was collected by using a questionnaire that was tailored to the research's objective. The questionnaires were distributed by using Google forms. The survey data analysis was analysed using SPSS software program. The variables for the research consisted of the frequency of sent and receive text via SMS, SMS usage, reliability of SMS, frequency of sent and receive text via OTT messaging applications, OTT messaging applications usage and its reliability.

The dependent variables will the score of SMS usage given by the respondents and the rest of the variables will be tested with the reliability and validity test with SPSS.

\section{RESULT AND DISCUSSION}

\subsection{Market Trend Analysis}

Figure 2 and 3 shown the market trend analysis based on the Short Message Service (SMS) volume which are gathered and analysed using the SPSS tool. The figure shown the decreased of volume for sending and receiving starting form Q1 2013 to Q4 2016.

With the coefficients that was calculated, a linear regression equation is as shown in the Figure 4.

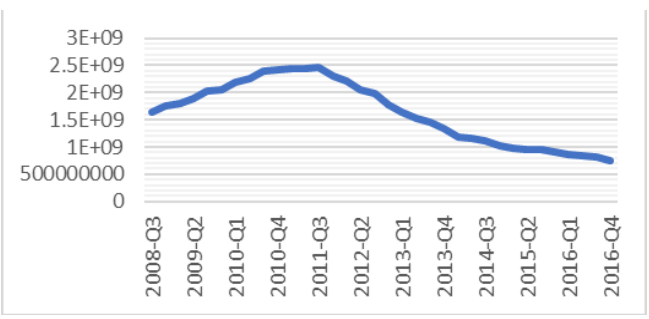

Figure 2. Data of Short Message Service (SMS) Volume Sent and Received Over a Mobile Network

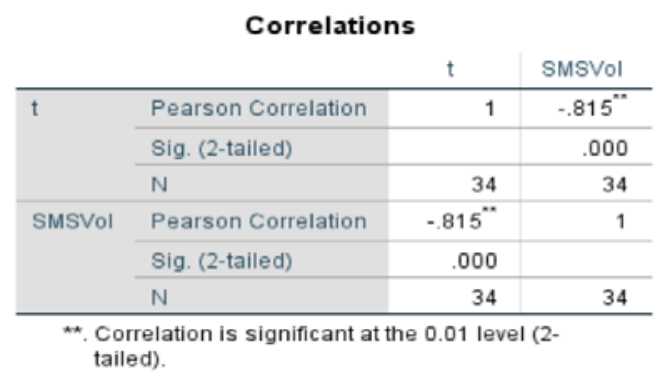

Figure 3. Output for Correlations 


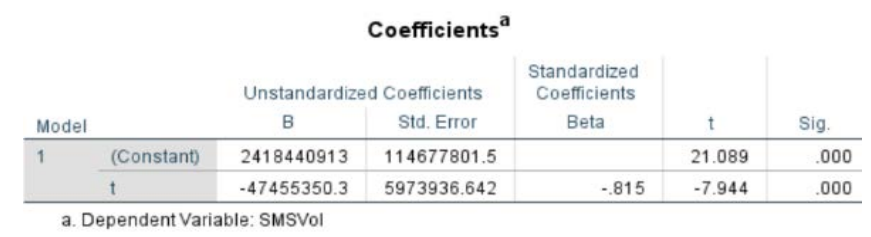

Figure 4. Output for Coefficients

$$
y=-47455350.3 x+2418440913
$$

The Equation (2) above was used to predict when SMS volume will equal to zero. This is done by finding the value of $x$ when $y=0$. The value of $x$ is 50.9 when $y=0$. This means by the 51 th quarter of the year starting from the third quarter of 2008, SMS technology will become obsolete. The predicted volume of SMS in the next four years is as shown in Figure 5 and 6.

\begin{tabular}{cc}
\hline Quarter of year & Predicted SMS Volume \\
\hline $2017-Q 1$ & 757503652.5 \\
$2017-Q 2$ & 710048302.2 \\
$2017-Q 3$ & 662592951.9 \\
$2017-Q 4$ & 567682251.3 \\
$2018-Q 1$ & 520226901 \\
$2018-Q 2$ & 472771550.7 \\
$2018-Q 3$ & 425316200.4 \\
$2018-Q 4$ & 377860850.1 \\
$2019-Q 1$ & 282950149.5 \\
2019-Q2 & 235494799.2 \\
$2019-Q 3$ & 188039448.9 \\
$2019-Q 4$ & 140584098.6 \\
$2020-Q 1$ & 93128748.3 \\
$2020-Q 2$ & 45673398 \\
$2020-Q 3$ & -1781952.3 \\
\hline
\end{tabular}

Figure 5. Predicted Short Message Service (SMS) Volume

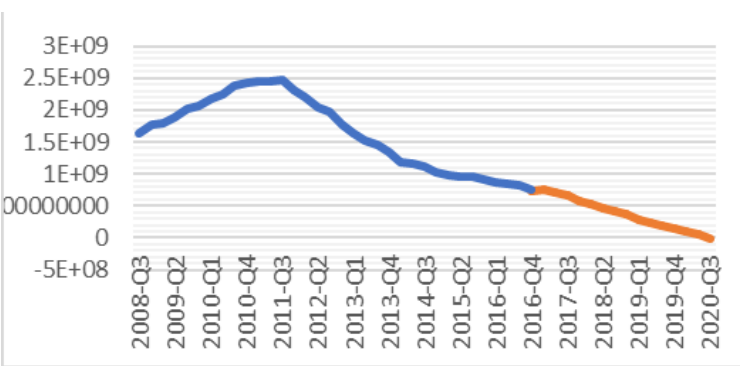

Figure 6. Short Message Service (SMS) Volume from 2008 to 2020

With the linear regression equation it is predicted that SMS will be disrupted by the third quarter 0f 2020. According to Cisco Visual Networking Index: Global Mobile Data Traffic Forecast Update, 2016-2021 mobile data, mobile data traffic grew by a whopping 63 percent in 2016 and by 2020 Monthly global mobile data traffic will be at 49 Exabyte's by 2021, and annual traffic will exceed half a zettabyte [12]. With the exponential growth data in the next 5 years can explain the prediction of the disruption of SMS. With data so widely use, OTT messaging application will only grow to be more reliable and popular. With SMS users can only be sending solely text messages to the recipient but with OTT messaging applications so many other added functionality that can be utilized.

Mckinsey \& Company listed down a few factors that may have led to the market lean more towards OTT messaging applications. One of the factors listed is technology readiness. Countries that possess 3G, better network and also a higher level of smartphone penetration will have an advantage [11]. Though with mobile usage data trends increasing at this excessive rate, it is no wonder SMS technology will be left behind. These are numbers for the growth of mobile social networking which further solidifies the position of OTT messaging applications. Users for social networking applications only keep increasing as shown in Figure 7 and 8.

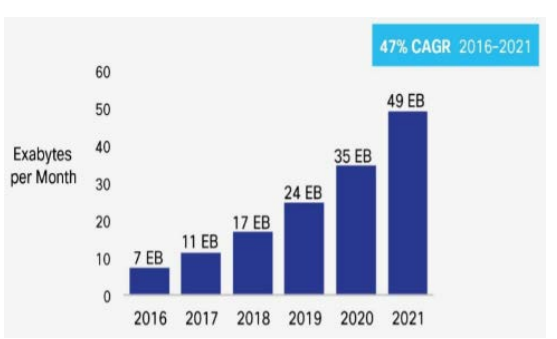

Figure 7. Mobile Data Forecasts by Cisco VNI

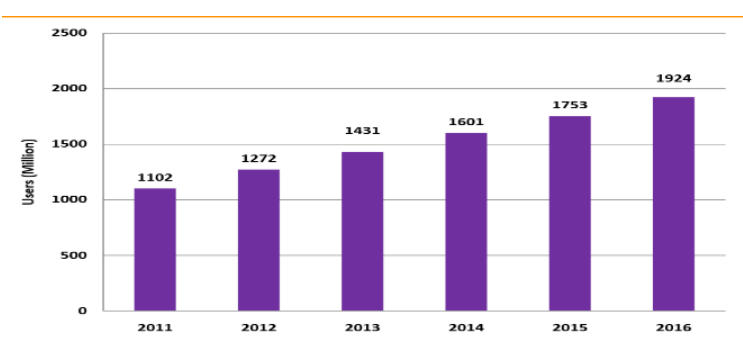

Figure 8. Growth of Mobile Social Networking User Numbers 2011-2016 [13] 


\subsection{Survey Analysis}

\subsubsection{Validity Test}

Firstly, the questionnaire was divided into two parts. The first part was for the frequency of send and received SMS, SMS usage and the reliability of SMS. The next part was about the OTT messaging applications on the frequency of send and received texts messages, OTT messaging applications usage and the reliability of OTT messaging applications. Validity test to measure how valid each of the question. Users were instructed to complete a Likert scale questionnaire and the data was then mined in SPSS.

All variables have been tested and have achieved a high positive correlation coefficient. With this it can be concluded that the variables are valid to the determinant of both SMS usage and OTT messaging applications usage (Figure 9 and 10).

\begin{tabular}{|c|c|c|c|c|c|c|}
\hline \multicolumn{7}{|c|}{ Correlations } \\
\hline & & T1 & $\mathrm{T} 2$ & T3 & T4 & TS \\
\hline \multirow[t]{3}{*}{$\mathrm{T} 1$} & Pearson Correlation & 1 & $.255^{\star}$ & $.521^{\mathrm{k}}$ & $.314^{\mathrm{k}}$ & $.806^{* x}$ \\
\hline & Sig. (2-tailed) & & .010 & .000 & .001 & .000 \\
\hline & $\mathrm{N}$ & 100 & 100 & 100 & 100 & 100 \\
\hline \multirow[t]{3}{*}{$\mathrm{T} 2$} & Pearson Correlation & $.255^{*}$ & 1 & .082 & .041 & $.575^{\mathrm{N}}$ \\
\hline & Sig. (2-tailed) & .010 & & .419 & .684 & .000 \\
\hline & $\mathrm{N}$ & 100 & 100 & 100 & 100 & 100 \\
\hline \multirow[t]{3}{*}{ T3 } & Pearson Correlation & $.521^{\prime \prime}$ & .082 & 1 & .184 & $.650^{\circ *}$ \\
\hline & Sig. (2-tailed) & .000 & .419 & & .067 & .000 \\
\hline & $\mathrm{N}$ & 100 & 100 & 100 & 100 & 100 \\
\hline \multirow[t]{3}{*}{ T4 } & Pearson Correlation & $.314^{\prime \prime}$ & .041 & .184 & 1 & $.570^{\prime \prime}$ \\
\hline & Sig. (2-tailed) & .001 & .684 & .067 & & .000 \\
\hline & $\mathrm{N}$ & 100 & 100 & 100 & 100 & 100 \\
\hline \multirow[t]{3}{*}{ TS } & Pearson Correlation & $.806 "$ & $.575^{\prime \prime}$ & $.650^{\prime \prime}$ & $.570^{* *}$ & 1 \\
\hline & Sig. (2-tailed) & .000 & .000 & .000 & .000 & \\
\hline & $\mathrm{N}$ & 100 & 100 & 100 & 100 & 100 \\
\hline
\end{tabular}

Figure 9. Correlations of SMS Usage

\begin{tabular}{|c|c|c|c|c|c|c|}
\hline \multicolumn{7}{|c|}{ Correlations } \\
\hline & & $\mathrm{T} 1$ & $\mathrm{~T} 2$ & $\mathrm{~T} 3$ & $\mathrm{~T} 4$ & TS \\
\hline \multirow[t]{3}{*}{ T1 } & Pearson Correlation & 1 & $.800^{\circ \prime}$ & $.664^{\prime \prime}$ & $.520^{\prime \prime}$ & $.891^{\prime \prime}$ \\
\hline & Sig. (2-tailed) & & .000 & .000 & .000 & .000 \\
\hline & $\mathrm{N}$ & 100 & 100 & 100 & 100 & 100 \\
\hline \multirow[t]{3}{*}{ T2 } & Pearson Correlation & $.800^{\prime \prime}$ & 1 & $.661^{\prime \prime}$ & $.442^{\prime \prime}$ & $.856^{\prime \prime}$ \\
\hline & Sig. (2-tailed) & .000 & & .000 & .000 & .000 \\
\hline & $\mathrm{N}$ & 100 & 100 & 100 & 100 & 100 \\
\hline \multirow[t]{3}{*}{ T3 } & Pearson Correlation & $.664^{\prime \prime}$ & $.661^{*}$ & 1 & $.429^{\prime \prime}$ & $.817^{\prime \prime}$ \\
\hline & Sig. (2-tailed) & .000 & .000 & & .000 & .000 \\
\hline & $\mathrm{N}$ & 100 & 100 & 100 & 100 & 100 \\
\hline \multirow[t]{3}{*}{ T4 } & Pearson Correlation & $.520^{\mathrm{k}}$ & $.442^{\prime \prime}$ & $.429^{\prime \prime}$ & 1 & $.754^{\prime \prime}$ \\
\hline & Sig. (2-tailed) & .000 & .000 & .000 & & .000 \\
\hline & $\mathrm{N}$ & 100 & 100 & 100 & 100 & 100 \\
\hline \multirow[t]{3}{*}{ TS } & Pearson Correlation & $.891^{\star n}$ & $.856^{\mathrm{k \prime}}$ & $.817^{\mathrm{kn}}$ & $.754^{\mathrm{kn}}$ & 1 \\
\hline & Sig. (2-tailed) & .000 & .000 & .000 & .000 & \\
\hline & $\mathrm{N}$ & 100 & 100 & 100 & 100 & 100 \\
\hline
\end{tabular}

Figure 10. Correlations of OTT Usage

\subsubsection{Reliability Test}

The reliability test came out poor for SMS usage. This may be due to the fact that even though users rarely use SMS, they receive a lot of unsolicited SMS. They also receive SMS from their respective banks for banking and some are even from the telecommunications company regarding their bills and payments. The reliability test for OTT messaging application came out at 0.838 which shows that the data is stable and reliable.

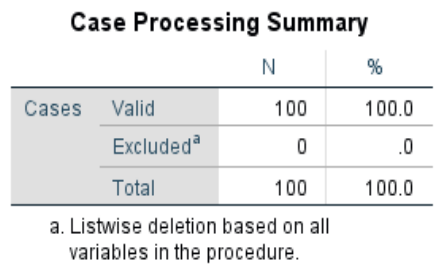

Figure 11. Case processing Summary

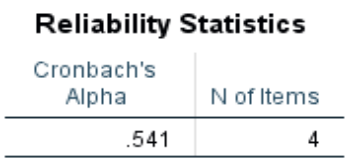

Figure 12. Reliability for SMS usage

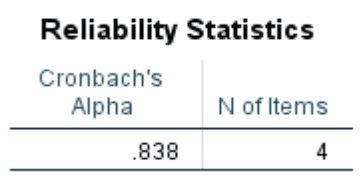

Figure 13. Reliability of OTT messaging applications

\subsubsection{Multiple Linear Regression Test}

To study the dependency of the dependent variable which is the score for SMS usage from the survey vs all other independent variables, a multiple linear regression must be implemented. This is because there is more than one independent variable. 


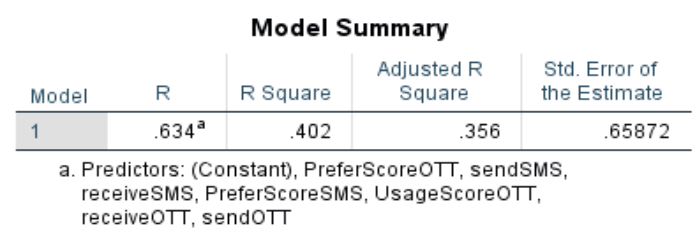

Figure 14. Model Summary of Multiple Linear Regression Test

1) Interpretation of Coefficient of Correlation (R)

The coefficient correlation noted as $\mathrm{R}$ measures the strength and direction of linear relationship of the dependent variable and all the independent variable. The value of $\mathrm{R}$ that was obtained is 0.634 . This shows a positive correlation amongst the independent variable vs the dependent variable. This is because a positive relationship is between 0.1 to 1 and negative relationship between -0.1 to 1 but when the value is equal to zero there is no correlation and in turn the closer it is to zero it signifies a weak correlation.

2) Interpretation of Coefficient of Determination(R2)

The coefficient of determination will determine how well the fit is with the variables for the regression model. The value of R2 is equal to 0.402 which suggests the independent variables in this regression model are only influencing the dependent variable by 40.2 percent. 59.2 percent of the dependent variable which is SMS usage is caused by external factors.

\section{CONCLUSION AND RECOMMENDATION}

Based on the results, it is very likely that the usage of Short Message Service (SMS) will drastically become obsolete. The prediction of disruption in SMS by the third quarter of 2020 is explained the exponential growth of mobile data usage and its reliability.

The finding from the survey showed that it has become a trend for businesses to use Short Message Service (SMS) as a marketing tool. Despite this user have showed that they much prefer using OTT messaging applications and find them a lot more reliable. Though this has not affected the decrease in Short Message Service (SMS) volumes from the initial introduction of OTT messaging applications in around 2011. Short Message Service (SMS) volumes have been steadily dropping since 2011 and it was possible to predict it ending because of this. With mobile data only improving it will be hard for a technology as static as Short Message Service (SMS) to compete.

For future work, it is recommended to analyse the market for OTT messaging applications and predict to what pace it will take to overcome the Short Message Service (SMS) market and ultimately replace it and disrupt the Short Message Service (SMS) technology. The market for OTT is expanding rapidly; it would give more insights to the topic if it was also analysed.

\section{REFERENCES}

[1] Bower J.L. and C.M. Christensen ; "Disruptive Technologies: Catching the wave”, Harvard Business Review, vol 73,iss. 1, pp.43-53, 1995.

[2] M. Weinberger, "After 9 years, the smartphone boom is finally over - Business Insider", Business Insider, 2016. [Online]. Available: http://www.businessinsider.my/idc-the-smartphone-boom-is-over-20169/?r=US\&IR=T\#AQ0u6FOcqe6JgWoo.97.

[3] S. Deffree, "1st text message is sent, December 3, 1992", EDN, 2016. [Online]. Available: http://www.edn.com/electronics-blogs/edn-moments/4402146/1st-text-message-is-sent--December-3--1992. [Accessed: 19- Dec- 2016]

[4] Adner R.; "When are technologies disruptive? A demand-based view of the emergence of competition", Strategic Management Journal, vol 23, iss. 8, pp.667-688, 2002.

[5] Govindarajan V. and P. K. Kopalle; "The usefulness of Measuring Disruptiveness of Innovations Ex Post in Making Ex Ante Predictions”, Journal of Product Innovation Management, vol 23, pp.12-18, 2006

[6] Hang C.C and D Yu; "A Reflective Review of Disruptive Innovation Theory,” Proc. of PICMET, South Africa, pp.402-414, 2008.

[7] F. Hillebrand, GSM and UMTS, 1st ed. Chichester: Wiley, 2002.

[8] B. Suarez, "So you think SMS is dying? Think again. | ZDNet", ZDNet, 2016. [Online]. Available: http://www.zdnet.com/article/so-you-think-sms-is-dying-think-again/.

[9] "Chetan Sharma: Technology \& Strategy Consulting", Chetansharma.com, 2016. [Online]. Available: http://www.chetansharma.com/usmarketupdateq32012.htm. 
[10] B. Chen, "Text Messaging Declines in U.S. for First Time, Report Says", Bits Blog, 2016. [Online]. Available: http://bits.blogs.nytimes.com/2012/11/12/text-messaging-declines-united-states/?_r=0.

[11] J Chavin et al., "The future of mobile messaging: Over-the-top competitors threaten SMS,” McKinsey \& Company, Inc. 2017

[12] “Cisco Visual Networking Index: Global Mobile Data Traffic Forecast Update, 2016-2021” Cisco Systems, Inc. San Jose, CA. 2017. 